\title{
Urgences
}

\section{Rocailles en automne}

\section{Yvette Francoli et Danielle Mazé}

Numéro 16, mars 1987

D.G. Jones : d'un texte, d'autres

URI : https://id.erudit.org/iderudit/025384ar

DOI : https://doi.org/10.7202/025384ar

Aller au sommaire du numéro

Éditeur(s)

Urgences

ISSN

0226-9554 (imprimé)

1927-3924 (numérique)

Découvrir la revue

Citer ce document

Francoli, Y. \& Mazé, D. (1987). Rocailles en automne. Urgences, (16), 42-43.

https://doi.org/10.7202/025384ar d'utilisation que vous pouvez consulter en ligne.

https://apropos.erudit.org/fr/usagers/politique-dutilisation/ 


\section{Yvette Francoli/Danielle Mazé ROCAILLES EN AUTOMNE}

Sous la bruine, ruine

d'ombres

tombe de fleurs

Le jardin recueille les couleurs

des feuilles mortes. Silence.

Les pierres fleurissent

comme s'ouvrent les tomes

où bruissent encore

les voix de ceux qui s'en sont allés

Peu à peu mes paroles

se font pierre

et fleurs

les ossements de mes pairs

Est-ce un dédale, un éden

ou Angkor-Vat

ou encore Thom cité profonde

à la nuit sombre? Forme

ni vivante ni morte

ni humaine. Je passe

dans la pluie, oribre brune

sur un pan de r'snes

Traduire la langue de notre "Colleague» dans celle de nos "pairs» ne fut pas chose aisée. Pourtant, c'est sans hésitation que nous l'avons suivi dans les dédales de ce passé archéologique, dans cette descente aux sous-sols de la conscience où résonnent tant de voix familières... Ici, les "Tombeaux des rois" d'Égypte et les "Remains of an Indian Village» ont cédé le pas aux «Ruines/Runes of a Cambodgian Temple/Jumble/Jungle»! Qu'importe, au crépuscule, toutes les rivières d'ombre remontent jusqu'aux sources du langage... 
Sur l'invitation du poète, nous avons donc joué avec les mots, les rimes intérieures, les allitérations, les contrastes. On y trouvera par exemple des sons mouillés et fluides: «ruines», "bruine», "nuit», «bruisse» s'opposant aux sons graves: «encore», «mort», «tome», «tombe», "sombre», "ombre» qui, tantôt sonnent comme des gouttes sur la pierre, tantôt résonnent comme des gongs appelant à la prière. D'où le choix du verbe "recueillir» pour traduire «It gathers the colours/ of fallen leaves», en raison de sa triple signification: «se recueillir sur une tombe», mais aussi "ramasser/rassembler en gerbe» et «recueil», synonyme de «tome».

Un point d'orgue s'imposait: «silence» pour «still» (conjonction ou adjectif) afin d'inviter le lecteur à se mettre à l'écoute de la nature. C'est ainsi que fleurissent les pierres, que vibrent les voix comme bruissent les feuilles de tomes (feuilles d'automne, cela va de soi!) et que les incunables s'ouvrent tels des sépultures pour laisser s'échapper les fantômes du passé. Après l'allitération de la sifflante "S», nous avons introduit la plosive "p" pour traduire l'image de cette bouche qui s'emplit de pierres, bredouille et peu à peu se pétrifie. Dans cette strophe, nous avons eu recours également à une inversion pour obtenir l'effet poétique et rythmique désiré.

«Dédale» nous a semblé exprimer à la fois la confusion de «jumble» et l'univers labyrinthique et inextricable de la «jungle», ainsi que les circonvolutions du cerveau où se perd la pensée. Sémantiquement, il s'oppose à "Eden». Phonétiquement, la lettre "d", sans sa triple répétition, évoque l'idée du bégaiement, des premiers balbutiements de l'histoire et l'hésitation du poète à formuler son interrogation.

Enfin, au risque de nous éloigner du texte - mais si peu! - nous n'avons pu résister au plaisir de «jongler» un peu plus avec les mots et de rendre à Angkor-Vat ce qui lui appartient, c'est-à-dire son enceinte d'Angkor-Thom transformée ici en «encore Thom» («encore-tombe» ou «encore-tome»?!), cité profonde au coeur de la «jungle» - ou du moi intérieur - et dont il ne reste que des «pans de ruines... ou de runes» sur lesquels se profile l'ombre mystérieuse du poète au terme de son voyage au bout de la nuit... Peut-être était-ce déjà lui qui hantait les ruines khmères quand nous les avons visitées, il y a près de vingt ans... Troublante impression de «déjà vu»! 